Communications in Physics, Vol.22, No. 4 (2012), pp. 357-364

\title{
MONITORING CIRRUS CLOUDS AND TROPOPAUSE HEIGHT OVER HANOI USING A COMPACT LIDAR SYSTEM
}

\author{
BUI VAN HAI, DINH VAN TRUNG, NGUYEN XUAN TUAN, \\ DAO DUY THANG, AND NGUYEN THANH BINH \\ Institute of Physics, VAST
}

\begin{abstract}
Cirrus clouds in the upper troposphere and the lower stratosphere have attracted great attention due to their important role and impact on the atmospheric energy balance. Because cirrus clouds are located high in the atmosphere, their study requires a high resolution remote sensing technique not only for detection but also for the characterization of their properties. The lidar technique with its inherent high sensitivity and resolution has become an indispensible tool for studying and improving our understanding of cirrus cloud. In this paper we describe the development of a compact and highly sensitive lidar system with the aim to remotely monitor for the first time the cirrus clouds over Hanoi (2101'42"N, 10551'12"W). From the lidar data collected during the year 2011, we derive the mean cloud height, location of cloud top, the cloud mean thickness and their temporal evolution. We found that the cirrus clouds are generally located at height between 11.2 to $15 \mathrm{~km}$ with average height of $13.4 \mathrm{~km}$. Their thickness is between 0.3 and $3.8 \mathrm{~km}$ with average value of $1.7 \mathrm{~km}$. Comparison between the location of the cloud top with the position of the tropopause determining from the radiosonde data shows good correspondance. We also compare the properties of cirrus clouds in our data with that observed at other locations around the world based on lidar technique.
\end{abstract}

\section{INTRODUCTION}

Cirrus clouds are optically thin, non-black, cold and located at high altitude clouds, which are mainly composed of ice crystals. These clouds affect the Earth's climate through two opposite effects: an infrared greenhouse effect by trapping out going infrared radiation and by reflecting solar radiation, preventing the heating of the lower atmospheric layers and the ground. The contribution of each effect depends strongly on the optical properties of cirrus clouds [1]. The interaction between these two effects is at the heart of the atmospheric energy budget. Therefore, the determination of the properties such as thickness, height and temperature of the cirrus layers has attracted great attention [2].

Cirrus clouds have been characterized in situ by aircraft [3], from space using satellite imagery or space observatories $[4,5]$. Although these studies provide valuable information on cirrus clouds, they have limitations on range resolution, temporal and spatial coverage. Therefore ground based remote sensing measurements are needed. The lidar technique with high sensitivity, high temporal and spatial coverage has become one of the most appropriate instruments for studying cirrus clouds.

Lidar has been used over the years to determine atmospheric parameters and to characterize the time and spatial evolution of the atmospheric boundary layers as well as to investigate the physical properties of the cloud composing particles $[4,5,6]$. For cirrus 
clouds, the physical parameters of interest that can be measured with lidar are thickness, altitude and temperature of the cirrus clouds. These parameters will provide important information on the cirrus cloud's radiative properties [7].

Vietnam is located in the tropical region and the frequent appearance of cirrus clouds is expected. However, there is no prior detailed study of the cirrus clouds using remote sensing technique. This contribution presents the first comprehensive lidar based cirrus cloud monitoring and analysis for Hanoi, Vietnam. The primary goal of this work augmented by the radiosonde data is to provide accurate and high resolution measurements of the main properties of cirrus clouds.

\section{LIDAR MEASUREMENT}

\section{II.1. Lidar system}

A compact lidar system has been developed for the present work at the institute of physics. The transmitter of the lidar system is based on the high power pulsed Nd: YAG laser Brilliant made by Quantel (France). The laser delivers a pulse energy of $180 \mathrm{~mJ}$ at 532 $\mathrm{nm}$ at a repetition rate of $10 \mathrm{~Hz}$, and a pulse duration of $5 \mathrm{~ns}$. The divergence of the laser beam is measured to be better than $1 \mathrm{mrad}$. The receiver is a $25 \mathrm{~cm}$ Cassegrain telescope $(\mathrm{f} / \mathrm{D}=10)$. To reduce the background light we limit the field of view of the telescope to $1.5 \mathrm{mrad}$ during the lidar measurement. Furthermore, to spectrally select the laser wavelength we use a high quality interference band pass filter of $3 \mathrm{~nm}$. The backscattered light is detected using photomultiplier tube R7400U from Hamamatsu (Japan). The signal is then digitized using a high speed 12 - bit ADC sampling at 20 MSPS. That sampling rate defines our vertical resolution of $7.5 \mathrm{~m}$.

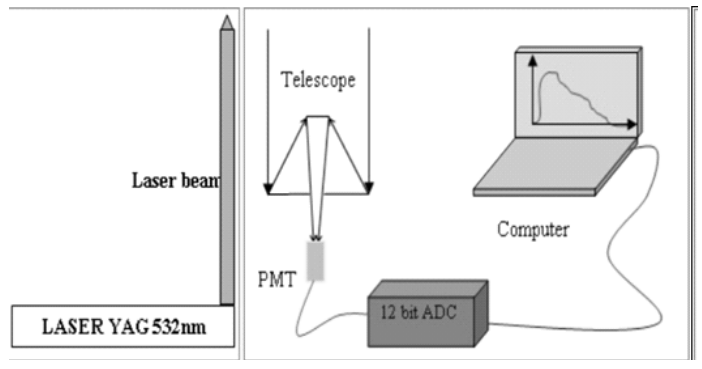

Fig. 1. Schematics of the lidar system

\section{II.2. Data analysis}

The strength of the detected lidar signal obeys the usual lidar equation [8]:

$$
P_{\text {Mie-Rayleigh }}(z)=P_{\text {Laser }} \cdot C \cdot \frac{A}{z^{2}} \cdot \beta(z) \cdot e^{-2 \cdot \tau \cdot(Z)},
$$

where $z$ is the vertical height, $P_{\text {laser }}$ is the transmitted laser power, $C$ is the calibration constant of the lidar system. $A$ is the collecting area of the receiving telescope, $\tau(z)$ is the extinction coefficient of the atmosphere, consisting of contribution of air molecules and aerosols, from the ground up to the scattering height $z . \beta(z)$ is the backscattering 
coefficient at the height $z$. $P_{\text {Mie-Rayleigh }}(z)$ is the detected lidar intensity From the above lidar equation we can deduce that the range-corrected signal $P_{M i e-R a y l e i g h}(z) . z^{2}$ is directly proportional to the backscattering coefficient $\beta(z)$, which is related to the number density of air molecules and particles in the atmosphere at the height $z$.

The lidar signal is measured by averaging over about 500 laser shots, corresponding to a time interval of 50 seconds. We then apply a three-step processing procedure of the lidar signal using a program written in Matlab: (i) remove time and intensity offset ; (ii) window-smooth the lidar signal to improve the signal to noise ratio, (iii) calculate the range corrected lidar signal to obtain $P_{\text {Mie-Rayleigh }}(z) . z^{2}$. The presence of high altitude cirrus clouds is found by visually inspecting the range corrected lidar signal. In Fig. 2a we show an example of the lidar signal with the clear presence of a cirrus cloud between height of $14-15.8 \mathrm{~km}$. We also show the expected lidar signal strength derived from the nearest radiosonde measurement of the atmospheric number density. It can be seen that above $3 \mathrm{~km}$ the measured lidar signal follows very closely the expected backscattering from pure air molecules, indicating that the atmosphere above $3 \mathrm{~km}$ is mostly molecular, i.e aerosols are entirely absent. Below $3 \mathrm{~km}$ the measured lidar signal is very strong and that is because of the presence of high concentration of aerosols in the boundary layer above the ground. Above $8 \mathrm{~km}$, when the lidar backscattering signal becomes stronger than that expected from molecular scattering alone, we define that positions as the boundary of the cirrus cloud. The result of this procedure is shown in Fig. 2a. This technique should be considered as a graphic method to detect the top and bottom height of the cirrus clouds with a confidence interval of about $500 \mathrm{~m}$ [9]. The mean height of the cirrus cloud is then defined by taking average of the position of the cloud top and the cloud bottom. The temperature of cirrus cloud is taken from the in-situ radiosonde measurements over Hanoi, which were carried out twice daily in the early morning and early evening. To determine the location of the tropopause from in-situ radiosonde data, we use the conventional thermal tropopause height definition as given by the Vietnam national remote sensing center. In our case, the tropopause height is simply calculated as the minimum of the vertical temperature profile as showed in Fig. $2 \mathrm{~b}$.

\section{RESULT AND DISCUSSION}

Cirrus cloud monitoring was carried out continuously for up to two consecutive hours for each measurement session. In Fig. 3 we show the temporal evolution of the observed cirrus clouds in two typical cases. On 23 September 2011 the cirrus cloud is detected from $13.5 \mathrm{~km}$ to $16 \mathrm{~km}$. The cloud shows considerable time variation in its geometrical thickness and the backscattering strength. The height of cloud top and cloud bottom are found to decrease with time. On 07 June 2011 the cirrus cloud consists of several distinct thin layers. The backscattering strength of each layer can be seen to vary considerably during the measurement period. Interestingly the cloud top remains stable during the whole measurement period of more than 3 hours.

Over the course of the year 2011 we recorded the presence of the cirrus cloud in 13 measurement sessions, mostly during the late autumn and early winter time (between October and December). From the collected lidar data we derived the main properties of 
Table 1. Top height, mean height, thickness and temperature property of cirrus clouds over Hanoi derived from lidar data.

\begin{tabular}{lcc}
\hline \hline Cloud property & Typical value & Measured range \\
\hline \hline Cloud top & $14.3 \mathrm{~km}$ & 11.8 to $16.5 \mathrm{~km}$ \\
\hline Mean height & $13.4 \mathrm{~km}$ & 12.5 to $14.3 \mathrm{~km}$ \\
\hline Thickness & $1.7 \mathrm{~km}$ & 0.3 to $3.8 \mathrm{~km}$ \\
\hline Temperature at the cloud top & $-65{ }^{\circ} \mathrm{C}$ & -79.3 to $-46^{\circ} \mathrm{C}$ \\
\hline \hline
\end{tabular}

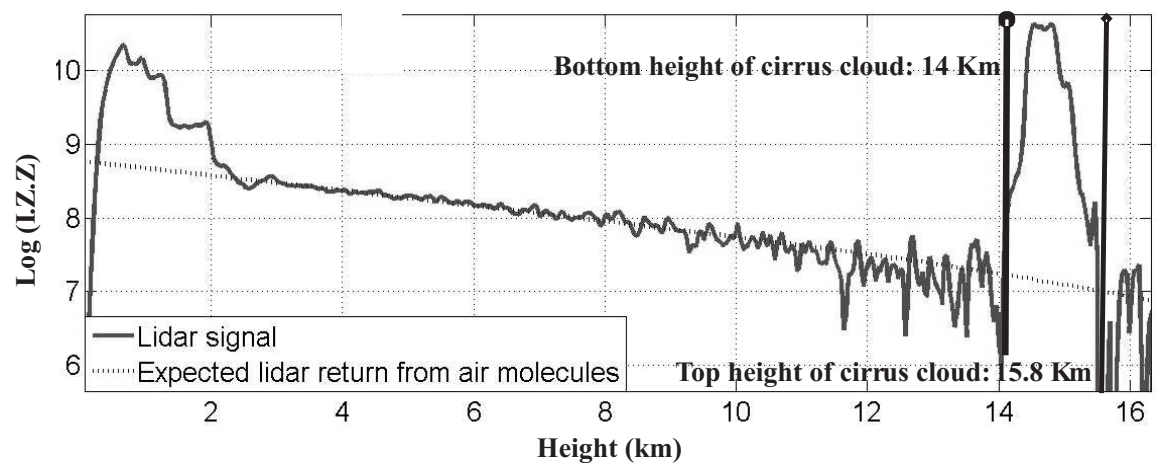

(a)

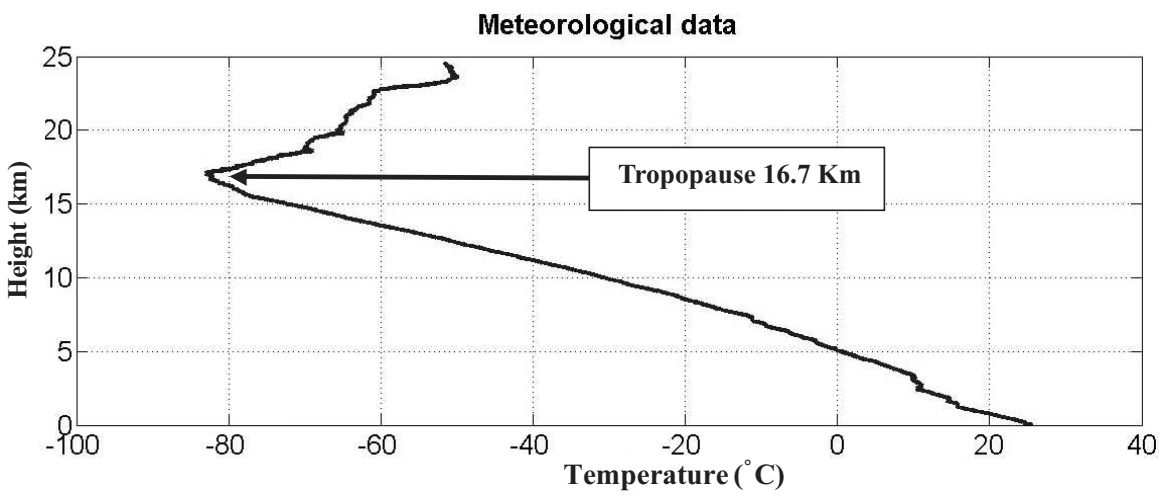

(b)

Fig. 2. (a) The range corrected lidar signal (dark solid line) obtained on 15 October 2011 and the expected lidar signal from the atmospheric molecules (broken line) calculated from radiosonde data. (b) The vertical temperature profile measured in - situ by radiosonde the next morning on 16 October 2011. The location of the tropopause at $16.7 \mathrm{~km}$ is also indicated by the arrow.

the cirrus cloud, namely cloud top height, mean height, geometrical thickness, temperature at the cloud top. We show the derived values of these parameters in Table 1. 


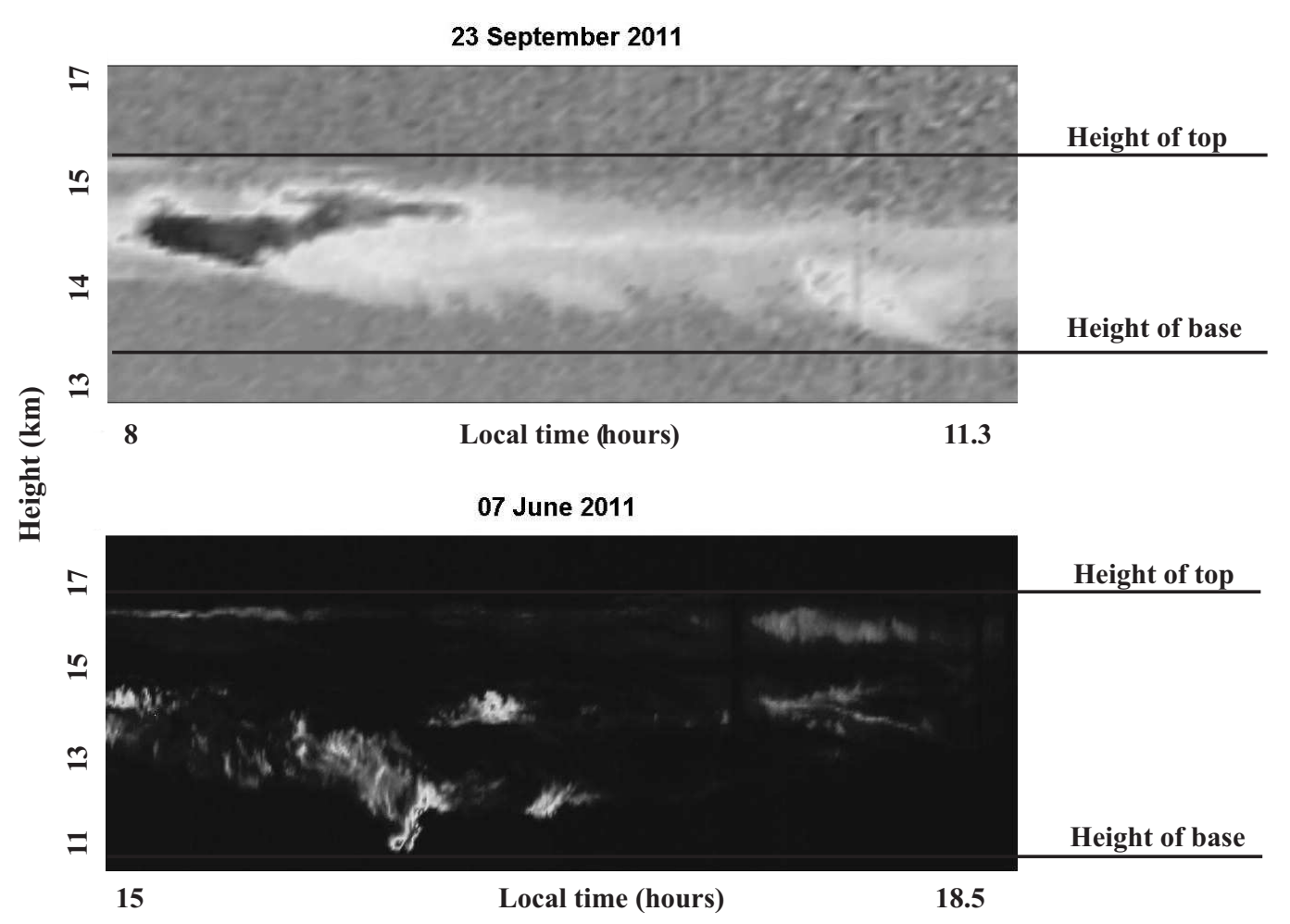

Fig. 3. Two cases of cirrus observation during the year 2011 over Hanoi. The color coded lidar signal at $532 \mathrm{~nm}$ has been range - corrected. The cloud top and cloud bottom are indicated by the thick dark lines.

In Fig. 3 we plot the distribution of the cirrus cloud top detected in our lidar measurements. As can be seen in the Fig. 3, most of the clouds are found between the height of $13 \mathrm{~km}$ and $16 \mathrm{~km}$ with a few outlying cases. From radiosonde data we estimate the tropopause height at the time of our lidar measurements. We found that the tropopause height varies between $16 \mathrm{~km}$ and $18.3 \mathrm{~km}$. The distance between the top cirrus cloud and the tropopause varies around the mean value of $2.8 \mathrm{~km} \pm 0.8 \mathrm{~km}$. the relationship between height of cirrus cloud and location of tropopause can be seen in Fig. 4. Therefore, from the top height of cirrus cloud we can indicate the height of located tropopause over Hanoi.

Because the radiative properties of cirrus cloud strongly depend on its temperature, mid-cloud temperature has been generally used for parameterizing $([5,9])$ their radiative properties. Figure 4 displays the distribution of the temperature of tropopause with height and the temperature at the top of the cirrus clouds for the cases detected in 2011 over Hanoi. Tropopause temperature was lower than cirrus cloud temperature for the in most cases from lidar system and meteorological data. The average temperature at the top of the cirrus clouds was found to be $-65^{\circ} \mathrm{C}$ and the temperature of tropopause was $-82^{\circ} \mathrm{C}$, corresponding to a temperature difference of about $17^{\circ} \mathrm{C}$. 


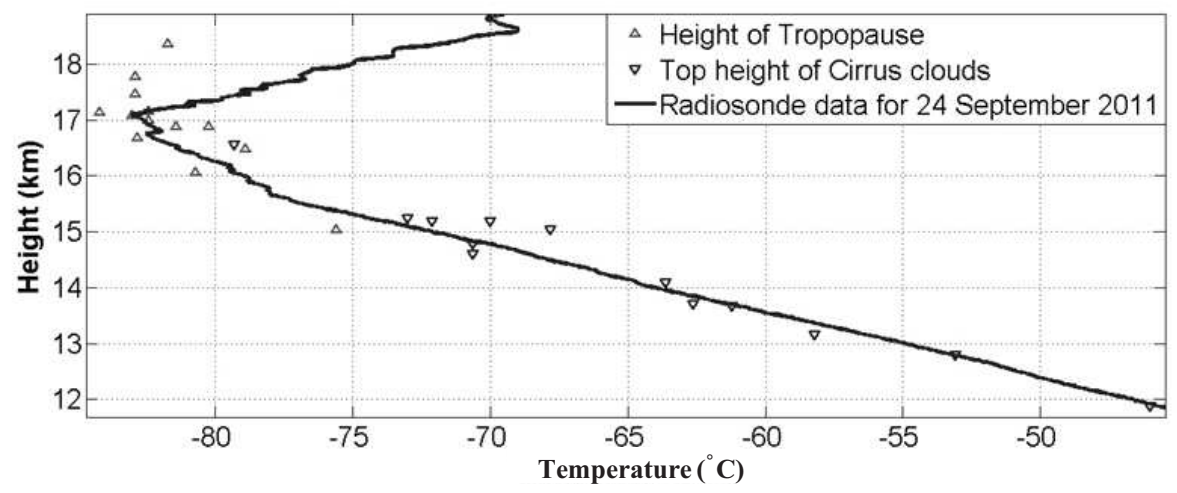

Fig. 4. Distribution of the cirrus clouds temperature and top height.

In Fig. 5 we show the distribution of the cirrus clouds thickness with the temperature at cloud top. Our data suggest that thicker clouds are more likely to have lower temperature. That also means thicker clouds are likely to be found at higher altitudes.

In order to identify similarities and differences in the cirrus cloud properties for different locations around the world, our results for cirrus clouds are compared with that derived from lidar data at other latitudes and showed in Table $2[10,11]$. The cirrus cloud over Hanoi located higher in the atmosphere than seen in other mid-lattitude locations such as Buenos Aries (Argentina) or OHP (France). However, the height of cloud top is statistically comparable to that found in Indoex experiment conducted in the tropical region. The cirrus cloud thickness derived from our data is also similar within the error bar to that found at other locations. Interestingly, the distance from the cloud top to the position of the tropopause seem to be larger. That is probably due to the geographical location of Hanoi, as the height and thickness of cirrus clouds are usually linked to their formation conditions in the atmosphere. The location of Hanoi might facilitate the formation of cirrus at higher altitudes.

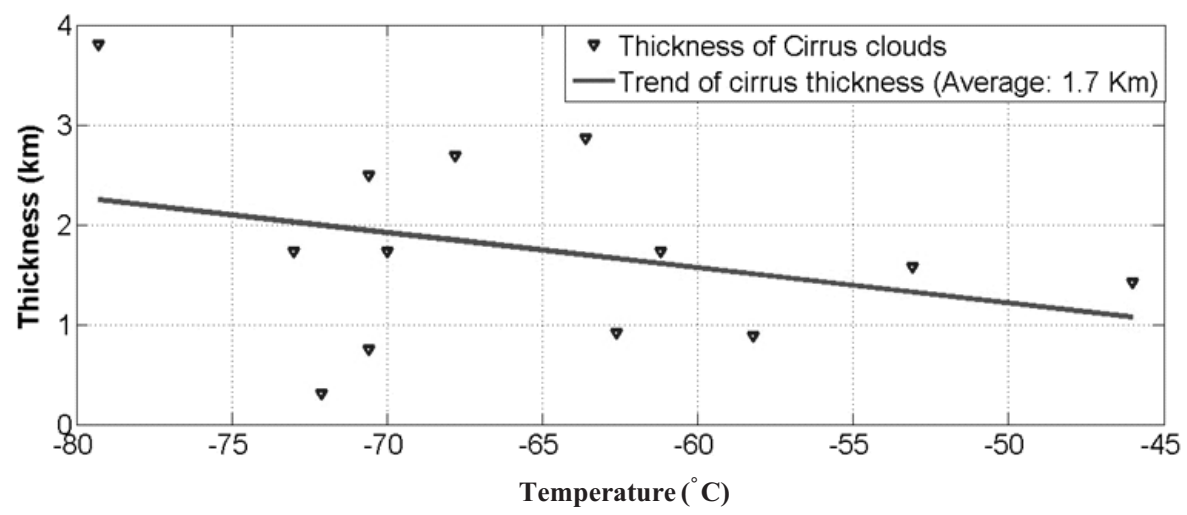

Fig. 5. Relationship of cirrus cloud thickness and cloud top temperature 
Table 2. Comparison of the main properties of cirrus clouds derived by lidar at different locations $[10,11]$.

\begin{tabular}{lccccccc}
\hline \hline Areas & $\begin{array}{c}\text { Buenos Aires } \\
{[10]}\end{array}$ & $\begin{array}{c}\text { Punta Arenas } \\
{[6]}\end{array}$ & $\begin{array}{c}\text { Prestwick } \\
{[6]}\end{array}$ & $\begin{array}{c}\text { OHP(fall }) \\
{[12]}\end{array}$ & $\begin{array}{c}\text { SLC } \\
{[9]}\end{array}$ & $\begin{array}{c}\text { INDOEX } \\
{[2]}\end{array}$ & $\begin{array}{c}\text { HANOI } \\
2011\end{array}$ \\
\hline \hline Location & $\begin{array}{l}34.6^{\circ} \mathrm{S} \\
58.5^{\circ} \mathrm{W}\end{array}$ & $\begin{array}{c}53.1^{\circ} \mathrm{S} \\
71^{\circ} \mathrm{W}\end{array}$ & $\begin{array}{c}55.5^{\circ} \mathrm{N} \\
4.6^{\circ} \mathrm{W}\end{array}$ & $\begin{array}{c}44^{\circ} \mathrm{N} \\
6^{\circ} \mathrm{E}\end{array}$ & $\begin{array}{c}41^{\circ} \mathrm{N} \\
112^{\circ} \mathrm{W}\end{array}$ & $\begin{array}{c}4.1^{\circ} \mathrm{N} \\
73.3^{\circ} \mathrm{E}\end{array}$ & $\begin{array}{c}21^{\circ} 01^{\prime} 42^{\prime \prime} \mathrm{N} \\
105^{\circ} 51^{\prime} 12^{\prime \prime} \mathrm{E}\end{array}$ \\
\hline $\begin{array}{l}\text { Cloud base } \\
\text { height }(\mathrm{km})\end{array}$ & $9.63(0.92)$ & $8.8(7.9)$ & $8.3(8.5)$ & 9.3 & 8.5 & $11.9(1.6)$ & $12.5(0.95)$ \\
\hline $\begin{array}{l}\text { Cloud top } \\
\text { height }(\mathrm{km})\end{array}$ & $11.82(0.86)$ & 9.5 & 9.6 & 10.7 & 11.1 & $13.7(1.4)$ & $14.3(0.99)$ \\
\hline $\begin{array}{l}\text { Cloud } \\
\text { thickness }(\mathrm{km})\end{array}$ & $2.41(0.95)$ & 1.4 & 1.2 & 1.4 & 1.9 & $1.8(1.0)$ & $1.7(0.73)$ \\
\hline $\begin{array}{l}\text { Distance to } \\
\text { tropopause }(\mathrm{km})\end{array}$ & $0.38(0.25)$ & 1.7 & 1.0 & $0.8(0.2)$ & 0.4 & - & $2.8(0.85)$ \\
\hline $\begin{array}{l}\text { Cloud top } \\
\text { temperature }\end{array}$ & $-64.5(3.6)$ & -49 & -48 & & -56 & $-65(11)$ & $-65(7)$ \\
\hline $\begin{array}{l}\text { Tropopause } \\
\text { temperature }\end{array}$ & $-60.6(4.7)$ & - & - & - & - & $-81(4)$ & $-82(1.1)$ \\
\hline \hline
\end{tabular}

\section{CONCLUSIONS}

In this paper we have described the development of a compact lidar system and the use of this lidar system to measure several properties of cirrus clouds in the upper atmosphere over Hanoi, Vietnam. Our study carried out over the year 2011 showed that: the cirrus cloud are found between 12.5 to $14.3 \mathrm{~km}$ and the average of the mean height is 13.9 $\mathrm{km}$ Interestingly, the distance between the cirrus clouds and the tropopause determined from radiosonde data remains fairly stable at $2.8 \mathrm{~km} \pm 0.8 \mathrm{~km}$, indicating that generally the top of cirrus clouds is a good tracer of the tropopause. The cirrus cloud's thickness is estimated to be between 0.3 and $5.8 \mathrm{~km}$ with the average value of $2.1 \mathrm{~km}$. Comparing with the same characteristics of cirrus cloud's measured at other locations around the world, we found that the cloud height appears to be similar to that of tropical cirrus, while the thickness value seems to be close to that of cirrus clouds at mid-attitudes. In the future, longer observation period spanning over several years would be needed to reach more definitive conclusions on the properties of cirrus clouds over Hanoi.

\section{ACKNOWLEDGMENT}

The financial support to the authors from Vietnam's National Foundation for Science and Technology Development (NAFOSTED) under contract 103.08-2010.26 is greatly acknowledged. We also thank Vietnam national remote sensing center for providing the radiosonde data.

\section{REFERENCES}

[1] K. N. Liou, Mon. Wea. Rev 114 (1986) 1167.

[2] P. Seifert, A. Ansmann, D. Muller, U. Wandinger, D. Althausen, A. J. Heymsfield, S. T. Massie, C. Schmitt, J. Geophys. Res. 112 (2007) D17205.

[3] J. Beyerle, H. J. Schafer, R. Neuber, O. Schrems, I. S. Macdemid, Geophys. Res. Lett 25 (1998) 919.

[4] A. Ansmann, U. Wandinger, M. Riebesell, C. Weitkamp, W. Michaelis, Appl. Opt 31 (1992) 7113 
[5] A. J. Heymsfield, C. M. R. Platt, J. Atmos. Sci. 41 (1984) 84

[6] F. Immler, O. Schrems, Geophys. Res. Lett. 29 (2002) 1809

[7] S. V. Sunilkumar, K. Parameswaran, J. Geophys. Res 110 (2005) D13205.

[8] M. M. Raymond, Laser Remote Sensing - Fundamentals and Applications, A Wiley-Intersciene Publication (1983) 47.

[9] K. Sassen, J. M. Comstock, J. Atmos. Sci. 58 (2001) 2113

[10] S. G. Lakkis, M. Lavorato, P. O. Canziani, Atmospheric Resarch 92 (2009) 18.

[11] S. G. Lakkis, M. Lavorato, P. O. Canziani, H. Lacomi, Atmospheric and Climate Sciences 2 (2011) 113.

[12] E. Giannakaki, D. S. Balis, V. Amiridis, and S, Kazadzis, Atmospheric Chemistry and Physics 7 (2007) 5519 .

Received 16 October 2012. 